\title{
Program Penerapan Mitigasi Bencana Gempa Bumi Di Ponpes Nurul Wathan Lombok Tengah NTB Berorientasi Pada Penurunan Magnet Bumi Akibat Pergerakan Sesar Patahan
}

\author{
Made Sutha Yadnya*1, Dwi Ratnasari ${ }^{2}$, Abdulah Zainuddin ${ }^{3}$, Bulkis Kanata ${ }^{4}$, Teti Zubaidah ${ }^{5}$, Paniran $^{6}$ \\ ${ }^{1}$ Electrical Enginnering, PUI Geomagnetic Laboratory, the University of Mataram, Lombok, Indonesia. \\ ${ }^{13465}$ Jurusan Teknik Elektro, Fakultas Teknik Universitas Mataram, NTB, Indonesia
}

\begin{abstract}
Article history
Received: 18-09-2020

Revised: 07-07-2020

Accepted: 24-11-2020

*Corresponding Author: Made Sutha Yadnya, Electrical Enginnering, PUI Geomagnetic Laboratory, the University of Mataram, Lombok, Indonesia;
\end{abstract}

Email: msyadnya@unram.ac.id

\begin{abstract}
The program that was implemented at Nurul Wathan (NW) was the result of research at the Rembitan Observatory to measure the earth's magnetism using a device called Proton. The international unit for measuring the earth's magnetism is the Tesla, specifically the nTesla earth magnet (Nano Tesla). The stages of implementing the solution are adjusted to the characteristics of the stages of the disaster cycle. During a disaster, full of activities in an emergency situation, post-disaster, reduce the complexity of the problems in reconstruction and rehabilitation. Pre-disaster requires thorough planning. Communities that are exposed to disasters are very diverse. For those who have been educated or those who have not received formal education, they need to understand the importance of disaster risk reduction (DRR).
\end{abstract}

Keywords: earth; emergency; magnet; cycle; pre-disaster

Abtrak: Program yang dilaksanakan dilaksanakan di Nurul Wathan (NW) merupakan hasil dari penelitian di Obsevatorium Rembitan untuk mengukur magnet bumi menggunakan alat yang disebut Proton. Satuan Internasional untuk mengukur magnet bumi adalah Tesla, khusus pada magnet bumi nTesla (Nano Tesla). Tahapan pelaksanaan solusi disesuaikan dengan karakteristik tahapan siklus terjadinya bencana. Saat bencana, padat aktivitas dalam suasana darurat, Pasca bencana, mereduksi komplikasi masalah yang rumit (complexity) dalam rekontruksi dan rehabilitasi. Pra bencana, perlu perencanaan yang menyeluruh. Masyarakat yang terancam bencana sangat majemuk. Bagi yang telah terdidik maupun yang masih belum tersentuh pendidikan formal perlu faham akan pentingnya pengurangan resiko bencana (PRB).

Kata Kunci: bumi; emergensi; magnet; siklus; pra-bencana

\section{PENDAHULUAN}

Gempa bumi kembali mengguncang Indonesia. Pada Minggu (29/07/2018) dini hari menjelang pagi, gempa berkekuatan magnitudo 6,4 SR mengguncang wilayah Pulau Lombok khusus regional Sumbawa. Rilis Badan Penanggulangan Bencana Nasional (BNPB) mengacu pada Badan Klimatologi dan Geofisika (BMKG) menyebutkan, episentrum gempa terletak di laut pada jarak 10 
$\mathrm{km}$ arah timur laut dari ibukota KLU pada kedalaman $10 \mathrm{~km}$. Gempa Besar ini terus berlanjut sampai 4 kali sehingga sampai 7 SR. Melihat rentetan gempa dalam beberapa bulan terakhir sampai bulan Agustus 2018 yang menyebabkan kerusakan bangunan cukup parah, parah dan sangat parah ada pola kesamaan dari jenis kedalaman gempa.

Dalam situasi dan karakteristik tempat tertentu, efek dari gempa ini dapat diklasifikasikan dengan gempa dangkal. Ini bisa terjadi karena tanah di daerah yang dihantam gempa tersusun oleh endapan kuarter dengan sedimen lunakm sehingga gelombang gempa di permukaan tanah bertambah kuat. Secara umum, gempa bumi terjadi di lapisan litosfer yang dihuni lempeng-lempeng tektonik. Gempa dapat terjadi ini pada lempeng samudera mendesak turun ke mantel bumi dari batas lempeng konvergen, dan lempeng samudera yang padat bertabrakan dengan lempeng benua yang kurang padat.

Pergerakan lempeng (sesar) bumi di Nusa Tenggara Barat (NTB) terus bergerak, karena NTB diapit oleh dua sesar yang panjang yaitu Sesar Flores disebelah Utara dan Sesar Pasifik disebelah Selatan. Sesar yang terus bergerak menyimpan energy karena tumbukan yang menyebabkan akan terjadi ledakan energi yang harus dikeluarkan sewaktu waktu, hal ini dapat dideteksi oleh penurunan nilai magnet bumi. Penurunan magnet bumi terjadi bila ada energi panas yang besar yang mengidikasikan bahwa ada pemicu (precursor) untuk terjadinya gempa bumi. Pada gambar 1.1 adalah peta yang menggambarkan daerah NTB diapit oleh 2 seear besar serta pada gambar 1.2 mengenai peta geologi Bali, NTB dan NTT (Zubaidah, 2018).

Nurul Wathan (NW) Sengkol berada pada Desa Sengkol, Kecamatan Praya Barat Daya Kabupaten Lombok Tengah Provensi Nusa Tenggara Barat. Ponpes ini berjarak 29 km dari Ibu kota Provensi (kota Mataram), jarak tempuh dapat dicapai dalam satu jam perjalanan sudah terdaftar sebagai lembaga pendidikan Pondok Pesantren modern, dengan memberikan fasilitas kepada anak didik sebaik mungkin. Jumblah santri cukup besar yaitu sekitar 200 siswa.

Pada kondisi gempa para siswa berserta pengelola Ponpes NW berhamburan tidak berhaturan untuk keluar gedung sekolah ini menyebabkan adanya bahaya bertabrakan antar siswa, belum adanya jalur evakuasi bila terjadinya gempa. Ini membutuhkan management mitigasi bencana yang baik dalam kondisi sebelum gempa, gempa sedang berlangsung dan sesudah gempa.

Management gempa demi keselamatan diperlukan sosilisasi yang tepat sesuai dengan situasi dan kondisi di Lapangan. Ponpes NW sangat memerlukan ini, dan kelompok riset EMTECH telah memiliki hasil kajian riset dan pelaksanaan pengabdian masyarakat salah satu contoh pelaksanaan di SMPN 2 Gangga KLU pada tahun 2014 dengan bantuan dana dari IbM (Iptek bagi Masyarakat) yang effektif telah dilakukan untuk meminimalis korban.

Belum adaya penegtahuan mengenai gempa oleh Ponpes NW untuk mitigasi gempa, dengan pengajuan serta disetujui proposal ini akan banyak diperoleh seperti peta lintasan keselamatan bila terjadi gempa, pengetahuan mengenai kemagnetan bumi, peta geologi Bali Nusa, serta salah satu dari pengenalan Universitas Mataram, Fakultas Teknik, Jurusan Teknik Elektro serta Kelompok Riset EMTECH (Zubaidah, 2010).

Managemen mitigasi bencana merupakanserangkaian upaya untuk mengurangi resiko bencana, baik melalui pembangunan fisik maupun penyadaran danpeningkatan kemampuan menghadapi ancaman bencana (UU No.24 Tahun 2007). Bencana alam seperti gempa bumi, tsunami, banjir, longsor, letusan gunung api dan lain-lain. Wilayah Indonesia, merupakan Negara kepulauan yang terletak pada pertemuan tiga lempeng tektonik dunia yaitu: lempeng Hindia-Australia di sebelah selatan, lempeng Eurasia di sebelah barat dan lempeng Pasifik di sebelah timur (BNPB) 
Pemerintah melalui BMKG dan Instansi terkait termasuk Perguruan Tinggi utamanya Universitas Mataram, khusus kelompok EMTECH memberi agar berpartisipasi serta menginformasikan kepada masyarakat setempat tentang partisipasi yang dapat diberikan dalam program mitigasi bencana. Kelompok EMTECH telah melakukan pengembangan konsep tentang partisipasi masyarakat terhadap mitigasi bencana. Langkah pertama untuk meningkatkan kesadaran masyarakat terhadap mitigasi bencana gempa bumi, terutama dalam partisipasi masayarakat diharapkan adanya kelancaran, kerjasama, simpatik dapat menimbulkan gairah dan dapat mengurangi kendala-kendala di lapangan pada saat pelaksanaan program mitigasi bencana. Ini merupakan manfaat yang diingikan serta akan diperoleh akan oleh Ponpes NW. Sosialisasi keberadaan Obsevatorium di Rembitan serta penggunaan dalam penelitian telah dilakukan sejak berdirinya. Hasil Pengukuran Obsevatorium Rembitan Dan Nurul Bayan Untuk Anomali Magnet Bumi Prediksi Gempa Bumi Pulau Lombok telah disosialisasi dengan baik (Yadnya et all, 2019).

\section{METODE}

Tahapan pelaksanaan solusi disesuaikan dengan karakteristik tahapan siklus terjadinya bencana. Saat bencana, padat aktivitas dalam suasana darurat, Pasca bencana, mereduksi kompli-kasi masalah yang rumit (complexity)dalam rekontruksi dan rehabilitasi. Pra bencana, perlu perencanaan yang menyeluruh. Masyarakat yang teran-cam bencana sangat majemuk. Bagi yang telah terdidik maupun yang masih belum tersentuh pendidikan formal perlu faham akan pentingnya pengurangan resiko bencana (PRB). Cara yang paling strategis untuk pendidikan PRB diperlukan melalui jalur pendidikan formal maupun informal. Pada gambar 2.1 mengagmbarkan sklus menggambarkan bencana tidak pernah akan berhenti. Dengan data empirik beberapa bencana dapat diperkirakan akan datang lagi misalnya banjir dan tanah longsor setiap musim hujan akan terjadi. Tsunami juga pasti akan terjadi lagi bila magnitude besar diatas 7 SR. Walaupun demikian, belum ada teknologi yang mampu mendeteksi secara akurat kapan gempa akan datang. Tsunami akan yang terjadi didahului gempa, dapat terdeteksi kapan sampai ke pantai karena kecepatan gelombang gempa lebih tinggi. Sebagai contoh, tsunami di Mentawai datang sampai pantai 25 menit setelah terjadi gempa 7,2 Skala Richter pada jarak $78 \mathrm{~km}$ arah Barat Daya Pulau Pagai Sela-tan, Mentawai. Kedalaman epicenter atau pusat gempa $10 \mathrm{~km}$, denganke-tinggian gelombang tsunami 4-6 m yang mencapai daratan sejauh 600 me-ter dari garis pantai. Tercatat jumlah korban tewas 413 jiwa, 270 jiwa luka berat dan 163 hilang (Saubani, 2010). Durasi waktu antara datangnya gempa dengan datangnya tsunami merupakan peluang untuk evakuasi penduduk da-lam menghindari bahaya tsunami. Teknologi, alur, posisi, kondisi, dan sistem yang akan digunakan masih dalam taraf uji coba dan semoga dapat berjalan untuk meminimalis korban jiwa maupun benda. 


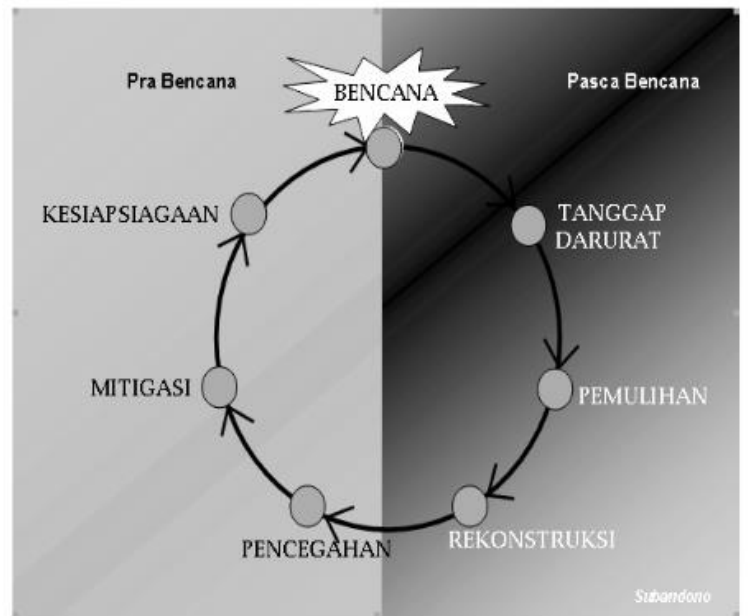

Gambar 1. Siklus dan Konsep Solusi Bencana (Suhardjo,2010.)

\section{HASIL DAN PEMBAHASAN}

Hasil penelitian dari group riset sudah banyak dipublikasikan baik diteingkat nasional maupun internasional. Metode yang digunakan adalah pemaparan hasil riset dan kejadian actual saat ini. Pembuatan peta mitigasi akan memperoleh informasi untuk jalur penyelamatan diri pada keadaan gempa dan sesudah gempa. Pengabdian dilaksanakan di Nurul Wathan (NW) Sengkol berada pada Desa Sengkol, Kecamatan Praya Barat Daya Kabupaten Lombok Tengah Provensi Nusa Tenggara Barat. Ponpes ini berjarak $29 \mathrm{~km}$ dari Ibu kota Provensi (kota Mataram), jarak tempuh dapat dicapai dalam satu jam perjalanan sudah terdaftar sebagai lembaga pendidikan Pondok Pesantren modern, dengan memberikan fasilitas kepada anak didik sebaik mungkin. Jumblah santri cukup besar yaitu sekitar 200 siswa.

Pengabdian dilaksanakan pada tanggal 2 Oktober 2019 dengan memulai berangkat dari Universitas Mataram jam 07.30 menggunakan transport mobil dan sepeda motor. Pengabdian dilaksanakan dengan melibatkan 4 mahasiswa yaitu: Aprialldi (2018), Alfin (2016), Kenya (2015), dan Widuan (2015).

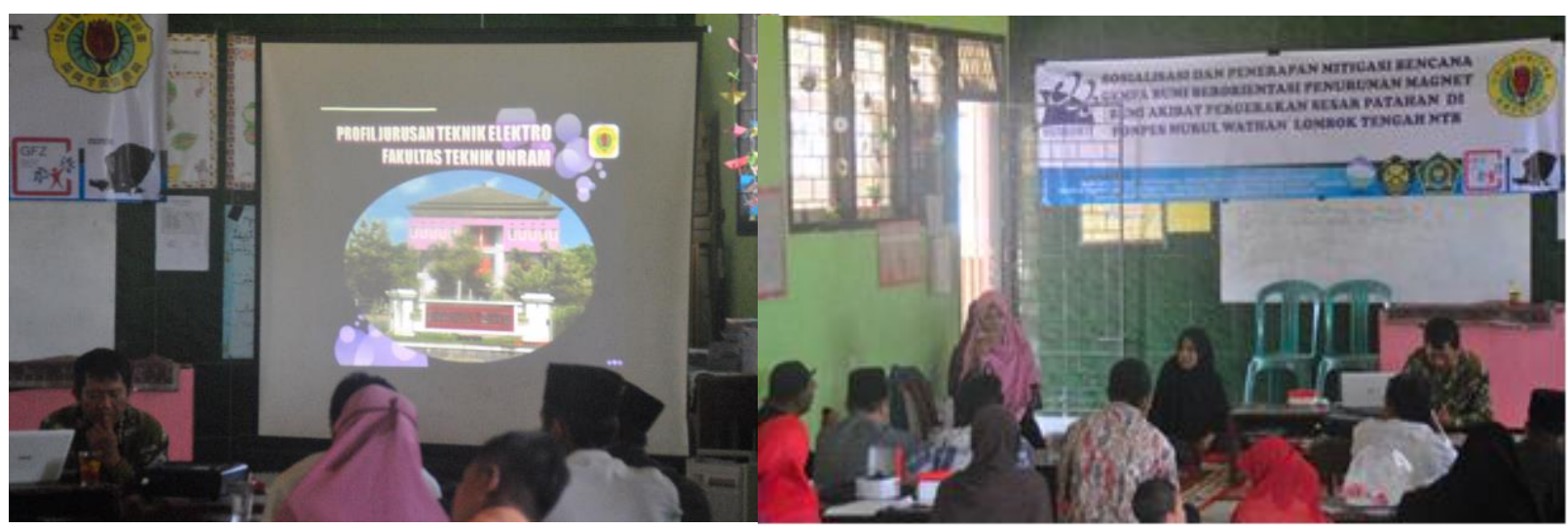

Gambar 2. Presentasi Sosialisasi serta Diskusi Sosialisasi di NW Lombok Tengah 


\section{KESIMPULAN DAN SARAN}

Kepedulian untuk melaksanakan Tri Dharma Perguruan Tinggi serta kalangan cendekiawan seabgai peneliti dapat bersatu untuk membatu masyarakat sebagai kepedulian dan penerapan hasil penelitian yang telah dilakukan untuk keselamatan umat manusia terhadap bahaya dan resiko terjadainya bencana alam yaitu gempa bumi. Kesipan untuk menggadapi bencana tersebut harus secara dini disosilisasi dengan baik.

\section{Ucapan Terima Kasih}

Terima kasih diucapkan kepada mahasiswa Teknik Elektro Universitas Mataram Aprialldi (2018), Alfin (2016), Kenya (2015), dan Widuan (2015). PUI Geomagnetik dan EMTECH mendokumentasikan kegiatan, serta semua yang tidak disebutkan satu persatu dalam membantu dan menfasilitasi peyelesaian makalah ini. Pembiayaan untuk publikasi ini sepenuhnya menggunakan dana DPP/SPP Teknik Elektro dan setoran setiap anggota Pengabdian pada Masyarakat. Semoga makalah ini dapat inspirassi dari kegiatan-kegiatan selanjutnyal.

\section{DAFTAR PUSTAKA}

Riza Rahardiawan dan Catur Purwanto 2014, "Struktur Geologi Laut Flores, NUSA TENGGARA TIMUR NTT". Jurnal Geologi Kelautan Volume 12 edisi April 2014

Sarmili Lili, Troa Rainer Arief .2014 "Keberadaan Sesar Dan Hubunga Dengan Pembentukan Gunung Bawah Laut Di Busur Belakang Perairan Komba Nusa Tenggara.”. Jurnal Geologi Kelautan Volume 12 edisi April 2014.

Suhardjo, D. dan Nugraheni, F. 2010. "Sustainable Livelihood Commu-nity Development as the Respond of the Earthquake Disaster". Enhancing Disaster Prevention and Mitigation. 1stInternational Confe-rence on Sustainable Built Environ-ment. ISBN 978-979-96122-9-8

Yadnya MS, Zubaidah, Kanata B, Paniran, Zainuddin, (2019) “Sosialisasi Pengukuran Obsevatorium Rembitan Dan Nurul Bayan Untuk Anomali Magnet Bumi Prediksi Gempa Bumi Pulau Lombok” Proseding PEPADU pp 237-242 Universitas Mataram.

Zubaidah T (2010) "Spatio-temporal characteristics of the geomagnetic field over the Lombok Island, the Lesser Sunda Islands region": New geological, tectonic, and seismoelectromagnetic insights along the Sunda-Banda Arcs transition. Scientific Technical Report of GFZ, STR10/07, ISSN 1610-0956, doi: 10.2312/GFZ.b103-10079.

Zubaidah T, Misbahuddin, Kanata B, Paniran, Rosmaliati, Yadnya MS, Riskia S (2018) Earth Magnetic Fields Evolution over Nusa Tenggara Region from Declination and Inclination Changes on Lombok Geomagnetic Observatory, The $2^{\text {nd }}$ International Conference on Applied Electromagnetic Technology (AEMT) 2018, Engineering Faculty of University of Mataram, Lombok. (IEEE Xplore Indexed). 